\title{
The Research and Practice of High Education Talent Cultivation Based on International Joint Teaching Mode
}

\author{
Xiaolei Wang \\ School of Fashion \\ Wuhan Textile University \\ Wuhan, China
}

\begin{abstract}
As the current international communication becomes more frequent, the industry requirement for innovative talents is becoming more intense. This paper relying on international cooperation and exchanges, explores the interactive teaching model based on international joint interactive teaching mode, summarizes the characteristics of interactive teaching mode and effectiveness in personnel training produced, for the establishment of innovative training model provides empirical research.
\end{abstract}

Keywords-interactive; creative talent; International Joint Teaching

\section{INTRODUCTION}

With the rapid development of social economy and culture, the increasingly frequent international industrial structure and employment structure of communication have undergone tremendous changes in the demand for talent, so a diversity evaluation index , such as extensive international perspective, strong ability to cope, a strong sense of social responsibility, good communication skills and teamwork ability to find and solve problems, etc., become the industry requirements for the current talent. but the teaching mode is still based on the traditional concept of indoctrination and training of stylized techniques based on teacher-led, student audience, the transmission of knowledge is still expressed as inheritance closed one-way transmission, this over-emphasis on teaching mode of knowledge and memory, the accumulation of existing knowledge and learning as the main content of education, seriously affected the cultivation of students' innovative consciousness, in this mode of talent cultivation of fashion not only a narrow range of knowledge, but also led to the talent no confidence in cross-cultural communication and no competitive power in international talent market. The students also appears weak in adapting to social changes such as psychological quality, competent and innovative aspects of ability to work, unable to meet the current and future pattern of China's garment industry under globalization.

Therefore, to explore current and future teaching model professional training apparel industry needs is crucial. Based interactive teaching model provides a good development idea

The Project Supported by Hubei Province Education Department 2012303 for us.

\section{INTERACTIVE TEACHING MODE}

Interactive Teaching (Reciprocal Teaching) is developed on the basis of an interactive theory, was first used by the American educational psychologist Brown and Palincsar (A.L.Brown \& A.S.Palincsar) proposed at improving students' reading comprehension and self-learning ability of, and later got further research and development, it is a teaching model developed in Scaffolding theory, interactive teaching is a kind of teaching methods widely used in Western countries. Interactive teaching is kind of teaching method at the macro scenario, diversity teaching methods are used in the teaching activities based on multi-platform and free-entry principle. Teachers and students take communication equally and independent interactive around a particular issue or topic. Interactive teaching mode changed a long-term traditional mode which is teacher-centered, students passively following pattern in the classroom teaching, the students are put on teaching activities center, stressed the importance of active learning in teaching and active exchanges and cooperation a number of interactive three-dimensional, the establishment of a teacher-student interaction, student-student interaction, vitality and diversity of teaching and other scenes. For teachers, the interaction is not only a teaching activity, it is equal dialogue with one or more groups in a particular context, a common share, build knowledge and understanding; For students, the interaction means open the door of the soul, show personality and ideas embodied subjectivity and creativity, and ultimately it enable teachers and students work together to explore some certain problems, helps to establish a new teacher-student relationship and the process of exploring achieve harmony and unity in all aspects.

\section{Practice InTERACTIVE TEACHING ModE}

Owing to stress on teaching situation of knowledge and skill application, interactive teaching model focuses on student learning initiative, reflecting the characteristics of constructivist learning, which is similar with art and design disciplines. Therefore we have explored new teaching mode from theory to practice through international cooperation based on interactive teaching mode in recent years and got 
some achievement, In recent five years we have taken international joint teaching with well-known universities of UK, USA, Australia, Japan, such as "traditional textile patterns and processes of modern design," with Edinburgh College of Art, "The United States state of well-known brands in the United States and China marketing surveys" and "waste recycling textile and apparel product development and market prospects investigation" with Iowa State University of USA , "designer brand and network marketing model study" and "Building a professional site features clothing," with Griffith University of Australia as well as "zero waste costume design study" with Japanese Bunka Gakuen University, and ultimately formed a teaching model based on characteristics of the interaction theory - international joint interactive teaching mode. This teaching model embodies the following characteristics.

\section{A. Set up International Interactive Teaching Based on International Cooperation}

Firstly, we selected some famous cooperation international institutions to launch the trial of the teaching model to expand the interaction of objects; in that case the traditional classroom pattern was completely broken. In international joint interactive teaching mode, students were divided respectively to several groups between home school and foreign schools, each home group corresponding with foreign group and they must complete the same project together. Each corresponding group need to expand interaction with other group so as to complete the task, therefore produce multi-interaction, such as Chinese students and teachers interacting, the interaction between Chinese students and foreign teachers, foreign students and teachers interaction, and interaction between home students and foreign students, not just face to face, but video, we-media tools, forms of communication are diversity and interesting.

\section{B. To Replace Traditional Individual Learning Model But Group Cooperative}

According to west Interactive teaching theory, learning is a process of communication and cooperation, learning theory of constructivism and humanism emphasizes consultation discussions and exchange of interactive learning between individuals and groups of learners, which helps students independent ability to learn and self-construction of knowledge. The students' mental contact of learning activities are constantly strengthened through positive exchange of information and emotional communication when they interact with home and foreign teachers, which is from psychological state of commonality, this commonality makes it mutual understanding and interest have related to each other, but also makes the interaction of trust between each other, which can achieve effective cooperative learning. In each of the international joint teaching, we allow students to group freely, realize each other by video and complete the teaching content in cooperative group.

\section{To Set up Interaction Between the Virtual and the Real Situation Based on Network Platform}

Through the Internet, extending the international interactive communication channels, expanding the scope of the classroom, this Internet-based interactive learning mode has gradually become the mainstream of learning, the network has the ability to provide two-way interaction, making it be a very unique and tremendous potential educational media. Teachers can be carried out in an electronic forum in instructional design, online teaching guidance and feedback, students can also use email, chat online discussions with fellow teachers. In each of the international joint interactive teaching, we will establish a qq group, the students and teachers joined them, real-time answers to student questions. Meanwhile interactive teaching for better implementation, we have established a professional video classroom, in order to ensure a weekly video communication normalization. In a joint teaching with Iowa State University (ISU), the school's Blackboard, an online discussion platform of ISU, also opened to our students to provide a platform for both teachers and students for discussions.

\section{To Change the Role of Teachers and Students to Promote the Diversification of Forms of Teaching}

In an interactive teaching, both teachers and students have changed their role. The teacher in the teaching activities are no longer just a provider of professional knowledge, but also plays the role of organizer and promotor who design and organize the activities of the task for the students, to guide students to solve the various problems encountered in learning activities as external guidance, and students are no longer passive recipients of knowledge, they communicate with each other through a variety of ways, cooperative learning, information exchange, to integrate themselves into learning environment among the interactive learning process to continuously improve their capabilities. Communicate with each other in order to share and progress together.

\section{E. To Train Cross-cultural Communication Skills Through Multicultural Interaction}

Cross-cultural communication skill is one of ability of current creative talents. It must be pointed out that crosscultural communication skills training is an important objective in international joint teaching. Byram, a American scholar, has emphasized that cross-cultural communication skills is the ability to think and attention to others speak and write lifestyle. A learner only has the common language skills is not enough, he or she should also have language and cultural knowledge to enable himself or herself to understand the other's language and way of thinking, ideas and values, thereby overcoming language and communication barriers caused by cultural differences in communication. In international joint interactive teaching, such as Britain, the United States, Japan, every country has their own cultural characteristics respectively. To understand their language and culture can help the smooth implementation of the project, therefore, in the project implementation process, students under the guidance of teachers' self-study language and culture of different country in order to implement effective 
cultural communication. But at same time, Byram also stressed that the learner should also maintain their home language and cultural identity, but not completely drop into the language and culture of the other country; we must enhance cultural self-confidence through cross-cultural exchange.

\section{THE SIGNIFICANCE OF THIS MODE FOR THE CULTIVATION OF INNOVATIVE TALENTS}

American scholar Pasuow proposed to cultivate innovative talents training system should follow the following principles:

- To develop student's effective thinking and skills and techniques to use the thinking;

- To help students acquire constantly changing knowledge and evolving and new information, to foster students an interest and desire to acquire knowledge continuously ;

- To promote students' ability to develop and use of the necessary documentation;

- To encourage students in learning creativity and independence;

- To promote the development of students' sense of independence and promote the understanding to other people, nature, culture as well as other things.

Therefore, the research of international joint interactive teaching model has achieved remarkable success in personnel training through six years research and practice. According to survey reflection of students' participated international joint teaching project, $98 \%$ participators consider that their knowledge expended; $96 \%$ students claim they are more confidence than before; $95 \%$ students believe this teaching mode is quite effective to encourage their creativity; $96 \%$ students hold their thinking ability to be improved; $97 \%$ students say the sense of team work to be strengthened. Research results shows that the international joint teaching based on interactive teaching mode provide a strong empirical basis for the teaching philosophy and teaching methods as well as other aspects of training model for the College to deepen the reform of education. We conclude the results as follows:

- To launch the teaching based on project, reasonable topics, to increase students' sense of social responsibility and cultural identity, to break the routine of book knowledge framework, the establishment of problem-oriented teaching mode.

- To set up teamwork, people-oriented, respect for students, respect for students' subjective perception of experience. To foster students' spirit of cooperation and collaboration as well as tolerance. Changing oneway teaching delivery to multi-way interactive transfer, proposing co-participation, to achieve a real sense of interactive learning.

- Establishing mechanisms for inquiry learning, studentcentered, teacher guidance, through surveys, literature searches, market research, data collection and other. Students analyze and solve problems, and sustainable learning and self-learning ability. For students in the learning process independently explore issues, research issues, analyze and solve problems, access to knowledge.

- Utilizing internet, built communication channels and platforms with foreign students and teachers, dialogue directly with overseas universities students and teachers through the network, and strengthen the oral communication skills and cross-cultural communication ability of students.

- The establishment of an interdisciplinary and crosscultural teaching system, complementary advantages, cultivating a spirit of cooperation, expanding student knowledge, understanding foreign culture to enhance further cultural self-confidence.

- To establish a teaching system based on graduate and undergraduate team. Graduate students lead undergraduate students so as to explore sustainable development mechanism and quality personnel training mode.

\section{CONCLUSION}

MIT, the famous American university insists to foster creative talent to adapt to the complex human society situation and contribute to social development. So we re-examine and build a interactive teaching mode standing on international joint teaching which is professional but jumping out the professional limitations, attention to the comprehensive quality of students personality, knowledge, quality, ability and quality. The teaching mode put Chinese students on the international teaching platform, not only to expand their international horizons, but also improve students' language ability, team spirit, professional vision as well as cultural confidence. The international joint mode has laid a good foundation for training creative talents with international competitiveness, but also an effective exploring of training mode for meeting industrial development in the future.

\section{REFERENCES}

[1] G. Eason, B. Noble, and I.N. Sneddon, "On certain integrals of Lipschitz-Hankel type involving products of Bessel functions," Phil. Trans. Roy. Soc. London, vol. A247, pp. 529-551, April 1955. (references)

[2] J. Clerk Maxwell, A Treatise on Electricity and Magnetism, 3rd ed., vol. 2. Oxford: Clarendon, 1892, pp.68-73.

[3] I.S. Jacobs and C.P. Bean, "Fine particles, thin films and exchange anisotropy," in Magnetism, vol. III, G.T. Rado and H. Suhl, Eds. New York: Academic, 1963, pp. 271-350.

[4] Zhou Shuang, based college English teaching and research interactive cultural infiltration theory, Northwestern Polytechnical University (Social Science Edition) December,2012.

[5] Tong Li, construction and practice of interactive teaching mode ----- to art and design disciplines, for example, global education and outlook, March 2012.

[6] Hou Xiaojie, policy-based interactive teaching of English-action theory

[7] university, Chifeng College (Natural Science), Feburay 2014. 
[8] Liu Zhen Fang, interactive teaching and research reviewed Journal of Distance Education, June 2009.

[9] Gui Yivan. Reconstruction of university personnel training quality education embodied [J]. Chinese higher education, September 2010.

[10] Chan Chun. Promote open education strategy to build a world-class university [J]. Chinese higher education, March 2010. 